level, if long continued, are associated with fatal ischaemia of vital organs in the presence of even moderate arterial thickening.

From the clinical aspect, the best guide in prognosis is the state of muscular tone as shown by posture, movements, and facial contours. The gradual hollowing of the cheeks in an old man who is getting worse acts as a warning to those about him. The way that a severe bronchitis is associated with the patient slumping and slipping down in bed, instead of sitting up comfortably, gives a signal of deterioration. The increasingly laboured movements of the aged patient, who grows gradually feebler, prepares doctor and nurse for approaching dissolution.

Apart from these two important guides, a test of value in cases where a neoplasm may be present is the sedimentation rate of the blood. Unless infection is present (such as bronchitis), marked increase of the sedimentation rate is usually associated with cancer. Rates below $20 \mathrm{~mm}$. in an hour (Westergren) almost certainly exclude a neoplasm.

A few points about prognosis in old age should be remembered. First of all, cardiac failure is a more serious proposition with less chance of complete temporary recovery than in middle age. Secondly, cancer is often slow in becoming an impediment to the patient. This is especially true where radium or deep X-ray therapy is employed. Thirdly, pneumonia is less serious than formerly when promptly treated by sulphapyridine, but still ranks high as a cause of subsequent cardiac failure. Finally, when a "cardiac" patient starts to get in and out of bed without any obvious reason, a fatal termination is not far off.

\title{
CORRESPONDENCE
}

\section{Medical Planning}

Sir,

I read with a great deal of pleasure your Editorial in the March issue of the Post-GraduAtE MEDICAL Journal. I am afraid that most leading articles in Medical. Journals assume a full-time salaried service is inevitable. The brethren of our profession are, we will be the first to admit, a mixed bag, but the majority of us practise Medicine because we obtain enjoyment from the work, work that is based fundamentally on the ideals of Hippocrates. There are dissenters it is true, but the man who enjoys his work automatically considers his patient first, whether in general practice or as a consultant. We admit we must be able to earn our meat and our drink, our house, and to raise our families, and we are allowed to do this in a way which is personal to each of us, hence we must be able to treat our patients, hold our own personal surgeries, work twenty-four hours a day if we wish, if only that we are able to attain happiness by working in this manner. One man may make a diagnosis at the first visit, another may visit twice or thrice before that diagnosis is made, for no doctor and no patient is alike, but if we are dictated to, if we have to work in Health Centres at fixed hours, if we cannot make up our own medicines, if we cannot work for the pleasure of the work, if the consultant cannot make more than a definite number of appointments per day, then we are no longer members of the medical profession, and all the principles and traditions of that profession will fall to the ground, and with that the standard of the men who enter in the future will be lowered.

The Medical Planning Commission was thrust upon many of us without consultation, many of us who had not seen a B.M.J. for months, many of us who had definite views on the profession before September r939, many of us who have seen how far short of medicine Service routine falls, and yet found unsurmountable difficulties to voicing an opinion anywhere. Medical men of the future have been thrust out of the country, and their protession is being twisted and turned by many who will practise little medicine after the war.

We agree that there is much that can be improved in the profession. We agree whole-heartedly with your Editorial that it is the middle-classes that are most affected when a transition from family doctor to consultant is called for, and that an expansion of the Panel Scheme to include the dependents you mention seems a satisfactory step forward at the moment. But, in the middle of total war, to consider undermining the general practitioner who, whatever authorities may state, still remains the backbone of the Profession, to convert this man from a Servant of the Public to a Civil Servant of a Ministry, where the patient and the work is a secondary consideration, is like re-building London by demolishing St. Paul's.

There are many young men who still retain some ideals in medicine, and these ideals have been strengthened while on Active Service despite lack of work at many times; they have no desire to return to civilian life to find themselves Civil Servants, and the sooner some form of organised opposition to combat the ministerial, materialistic, undemocratic methods that are being used at present the better, and it is to young Post-graduate members who are interested in Medicine as an Art that the Service doctor must turn to at the moment.

I am, your obedient servant, Northage J. DE V. Mather, Surgeon-Lieutenant, R.N.V.R. 